\title{
AVALIAÇÃO DO USO DE TANINO EM PH NEUTRO NO TRATAMENTO DE EFLUENTE DE CURTUME
}

\author{
Cássio Tamogami ${ }^{1}$
}

Maria Cristina Rizk ${ }^{2}$

\author{
Talita Souza de Almeida ${ }^{3}$
}

\begin{abstract}
RESUMO
O efluente gerado no processo produtivo de curtimento de couro é rico em material orgânico, sal, sulfetos, corante, cromo potencialmente tóxico, entre outros poluentes que causam impactos ao solo, água e ar. $\mathrm{O}$ tratamento mais comum dado ao efluente de curtume consiste em gradeamento e retenção de gordura seguido de coagulação, floculação, decantação e aplicação de lodos ativados. O objetivo do presente estudo foi tratar o efluente de curtumes por meio do processo de coagulação/floculação/decantação com o coagulante natural tanino. $\mathrm{O}$ pH do efluente foi ajustado para 7,0 e as concentrações de tanino testadas variaram de 0,6 a 3,6 g/L. Após a decantação, foi coletado o sobrenadante e analisado em termos de remoção de DQO, cor e turbidez. Pôde-se observar que houve eficiência na remoção de quase $100 \%$ de cor e turbidez utilizando tanino. Em relação à $D Q O$, as remoções foram menores que as remoções de cor e turbidez, ficando em torno de $50 \%$.
\end{abstract}

PALAVRAS-CHAVE: Efluente de curtume; coagulação/floculação/decantação; coagulante natural.

\section{EVALUATION OF THE TANNIN USING IN PH NEUTRAL IN THE TANNERY WASTEWATER TREATMENT}

\footnotetext{
ABSTRACT

The effluent generated in the production process of tanning leather is rich in organic material, salt, sulfides, dye, potentially toxic chromium, among other pollutants that cause impacts to soil, water and air. The most common

1 Engenheiro Ambiental, Universidade Estadual Paulista "Júlio de Mesquita Filho" campus de Presidente Prudente. cassio_tamogami@hotmail.com

2 Engenheira Química, Professora Assistente Doutora, Universidade Estadual Paulista "Júlio de Mesquita Filho" campus de Presidente Prudente.crisrizk@fct.unesp.br

3 Graduanda em Engenharia Ambiental, Universidade Estadual Paulista "Júlio de Mesquita Filho" campus de Presidente Prudente. tyta_almeida@hotmail.com
} 
treatment of the tannery wastewater consists of railing and fat retention followed by coagulation, flocculation, sedimentation and application of activated sludge. The aim of this study was to treat the effluent from tanneries through coagulation/flocculation/sedimentation with the natural coagulant tannin. The effluent $\mathrm{pH}$ was adjusted to 7.0 and tannin concentrations tested ranged from 0.6 to $3.6 \mathrm{~g} / \mathrm{l}$. After decantation, the supernatant was collected and analyzed in terms of COD removal, color and turbidity. It was observed that removal efficiency was almost $100 \%$ of color and turbidity removal using tannin. Regarding COD removals were lower than the color and turbidity, getting around $50 \%$.

KEY-WORDS: Tannery effluent. Coagulation/flocculation/sedimentation. Natural coagulant.

\section{EVALUACIÓN DEL USO DE TANINO PH NEUTRO EN EL TRATAMIENTO DE AGUAS RESIDUALES DE BRONCEADO}

\section{RESUMEN}

El efluente generado en el proceso de producción de cuero curtido es rico en materia orgánica, sal, sulfuros, tinte, potencialmente tóxicos de cromo, entre otros contaminantes que causan impactos al suelo, agua y aire. El tratamiento más común de las aguas residuales curtiduría consta de barandilla y la retención de la grasa seguido por coagulación, floculación, sedimentación y la aplicación de lodos activados. El objetivo de este estudio fue para tratar el efluente de las curtidurías a través de la coagulación/floculación/sedimentación con proceso de tanino natural coagulante. El pH del efluente se ajustó a 7,0 y el tanino concentraciones ensayadas oscilaron entre 0,6 y 3,6 g / I. Después de la decantación, el sobrenadante se recoge y se analiza en términos de remoción de DQO, color y turbidez. Se observó que la eficiencia de eliminación era casi $100 \%$ de color y turbidez usando tanino. En cuanto a las extracciones de DQO fueron más bajos que el color y la turbidez, obteniendo alrededor del $50 \%$.

PALABRAS-CLAVE: Aguas residuales de curtiembre. Coagulación/floculación/sedimentación. Coagulante natural.

\section{1 - INTRODUÇÃO}

A maior parte dos impactos ambientais gerados pela sociedade contemporânea de países desenvolvidos ou em desenvolvimento tem sua gênese no setor industrial. Esse setor é um grande consumidor de recursos naturais e um grande produtor de dejetos que, geralmente, são descartados no meio ambiente, no estado in natura ou ineficientemente tratados, em especial nos ecossistemas aquáticos. As indústrias de curtimento de couro são valorosas representantes do extraordinário potencial poluidor do segmento industrial (PASCOAL et al., 2007).

A liberação descontrolada de efluentes de curtume em corpos d'água naturais aumenta a poluição ambiental e os riscos à saúde. As características do efluente de curtume variam amplamente, dependendo da natureza do processo de curtimento, da 
quantidade de água utilizada, do processo de preservação da pele, da capacidade de processamento de couro, e da ausência de medidas para a minimização de água utilizada (KURT et al., 2007).

Freitas e Melnikov (2006) destacam que as características convencionais dos poluentes das diversas etapas do processo de curtimento de couro são: demanda bioquímica de oxigênio $\left(\mathrm{DBO}_{5}\right)$ - $1.600 \mathrm{mg} / \mathrm{L}$; demanda química de oxigênio (DQO) $4.600 \mathrm{mg} / \mathrm{L}$; sulfitos - $64 \mathrm{mg} / \mathrm{L}$; cromo total - $76 \mathrm{mg} / \mathrm{L}$.

Geralmente, a primeira etapa do tratamento de efluentes contendo metais pesados é a coagulação química a qual, provavelmente, influencia significativamente as etapas de tratamento subsequentes. O processo de coagulação/floculação tem por finalidade a remoção de substâncias coloidais, ou seja, material sólido em suspensão (cor) e/ou dissolvido (turbidez). Essa operação normalmente é considerada como um pré-tratamento que objetiva o condicionamento do despejo para o tratamento subsequente (Vaz et al., 2010).

O uso de polímeros naturais como coagulantes vem sendo amplamente estudado por apresentar inúmeras vantagens com relação aos agentes químicos, principalmente quanto à biodegradabilidade, baixa toxicidade e baixo índice de produção de lodo residual (CARVALHO, 2008).

O tanino é um coagulante vegetal efetivo numa ampla faixa de $\mathrm{pH}$, que elimina o uso de alcalinizantes (como soda ou cal), não acrescenta metais ao processo e proporciona uma redução no volume de lodo a ser descartado. Ainda, devido a sua composição orgânica, pode ser biologicamente degradado ou eliminado termicamente (ÖZACAR e SENGIL, 2003).

Diante do exposto, o presente estudo teve como objetivo geral a avaliação do tratamento de efluente de curtume, em pH neutro, no processo de coagulação/floculação/decantação, utilizando coagulante natural tanino.

\section{2 - DESENVOLVIMENTO}


A seguir, estão apresentadas a metodologia e os resultados e discussões obtidos nesta pesquisa.

\section{1 - Metodologia}

O efluente utilizado no estudo foi coletado num curtume oeste paulista, que faz o curtimento parcial do couro desde a fase "wet-blue" até a fase de acabamento. O efluente foi acondicionado em galões de polietileno de 5 litros e mantido sob refrigeração em temperatura abaixo de $10^{\circ} \mathrm{C}$ até a sua caracterização $(\mathrm{pH}, \mathrm{DQO}$, cor e turbidez) e realização dos experimentos.

Inicialmente, o pH do efluente foi ajustado para 7,0 utilizando solução diluída de ácido clorídrico. $\mathrm{O} \mathrm{pH}$ foi determinado pelo método potenciométrico com auxílio de um pHmetro da marca HANNA® modelo HI 221.

Em aparelho jar test (Figura 1), realizou-se os ensaios de coagulação/floculação/decantação, utilizando uma solução diluída de 1:10 de tanino comercial.

As concentrações de coagulante testadas foram: 0,$6 ; 1,2 ; 1,8 ; 2,4 ; 3,0$ e 3,6 $\mathrm{g} / \mathrm{L}$. Foi utilizado o tempo de 1 minuto e 30 segundos e gradiente de $120 \mathrm{rpm}$ para a mistura rápida e o tempo de 15 minutos e gradiente de $20 \mathrm{rpm}$ para a mistura lenta. $\mathrm{O}$ tempo de decantação utilizado foi de 20 minutos. Posteriormente, retirou-se o sobrenadante que foi submetido à análise de DQO, cor e turbidez.

Os ensaios foram realizados em réplica e os resultados foram lidos em duplicata. 
Figura 1: Ensaio de coagulação/floculação/decantação em jar test

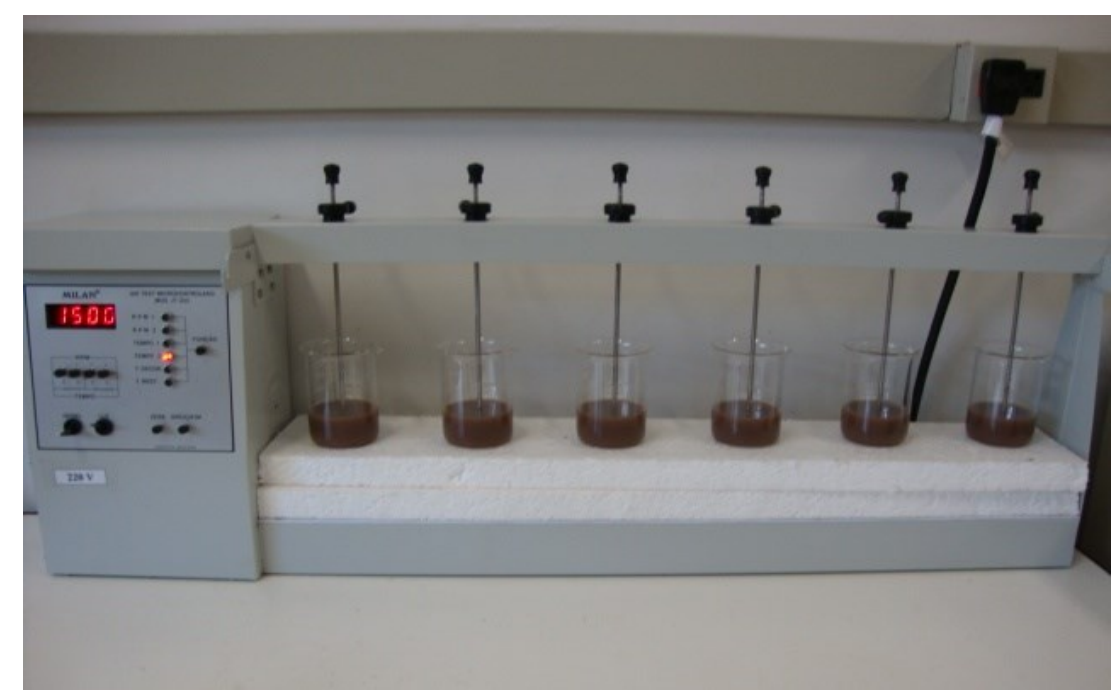

A DQO foi determinada segundo a metodologia apresentada pelo Standard Methods for the Examination for Water and Wastewater (APHA, 1998), que se baseia na oxidação da matéria orgânica por 2 horas de aquecimento em presença de meio ácido $\left(\mathrm{H}_{2} \mathrm{SO}_{4}\right)$ e dicromato de potássio $\left(\mathrm{K}_{2} \mathrm{Cr}_{2} \mathrm{O}_{7}\right)$. Após a digestão da amostra, a DQO foi determinada com o auxílio de um espectrofotômetro da marca $\mathrm{HACH} \otimes$ modelo DR 3900.

A cor aparente também foi determinada com o auxílio do espectrofotômetro da marca $\mathrm{HACH} \otimes$ modelo DR 3900 , que utiliza o método padrão platina/cobalto a 455 $\mathrm{nm}$, previamente calibrado com água destilada.

A determinação da turbidez foi realizada no turbidímetro da marca HANNA ${ }^{\circledR}$ modelo HI 88703 para a leitura de forma direta, com os resultados expressos em NTU (Unidade Nefelométrica de Turbidez), previamente calibrados com soluções padrão de calibração.

\section{2 - Resultados e discussão}

A Tabela 1 apresenta a caracterização do efluente bruto. 
Tabela 1: Caracterização do efluente bruto

\begin{tabular}{lc}
\hline \multicolumn{1}{c}{ Parâmetros } & Valores \\
\hline Cor Aparente $\left({\left.\mathrm{mg} \mathrm{PtCo} . \mathrm{L}^{-1}\right)}\right.$ & 4.420 \\
Demanda Química de Oxigênio $\left(\mathrm{mg} \mathrm{O}_{2} \cdot \mathrm{L}^{-1}\right)$ & 1.732 \\
$\mathrm{pH}$ & 7,82 \\
Turbidez (NTU) & 547 \\
\hline
\end{tabular}

A caracterização do efluente apresentou valores de DQO de $1.732 \mathrm{mg} \mathrm{O}_{2} \cdot \mathrm{L}^{-1}$, turbidez de 547 NTU e cor aparente de $4.420 \mathrm{mg} \mathrm{PtCo.L}^{-1}$. Assim, observa-se que a carga orgânica oxidável no efluente é relativamente baixa, quando comparada com outras pesquisas. Essa característica pode ser devida ao fato do curtume em análise fazer apenas o curtimento parcial do couro, não contemplando as etapas iniciais do processo, onde se produz a maior parte da matéria orgânica (gordura, sangue), característica do efluente de curtume. Quanto à turbidez e à cor aparente, os valores encontrados foram altos, podendo estes serem relacionados com a alta quantidade de sólidos na amostra.

A remoção de cor utilizando o coagulante natural está apresentada na Figura 2.

Figura 2: Remoção de cor aparente utilizando tanino

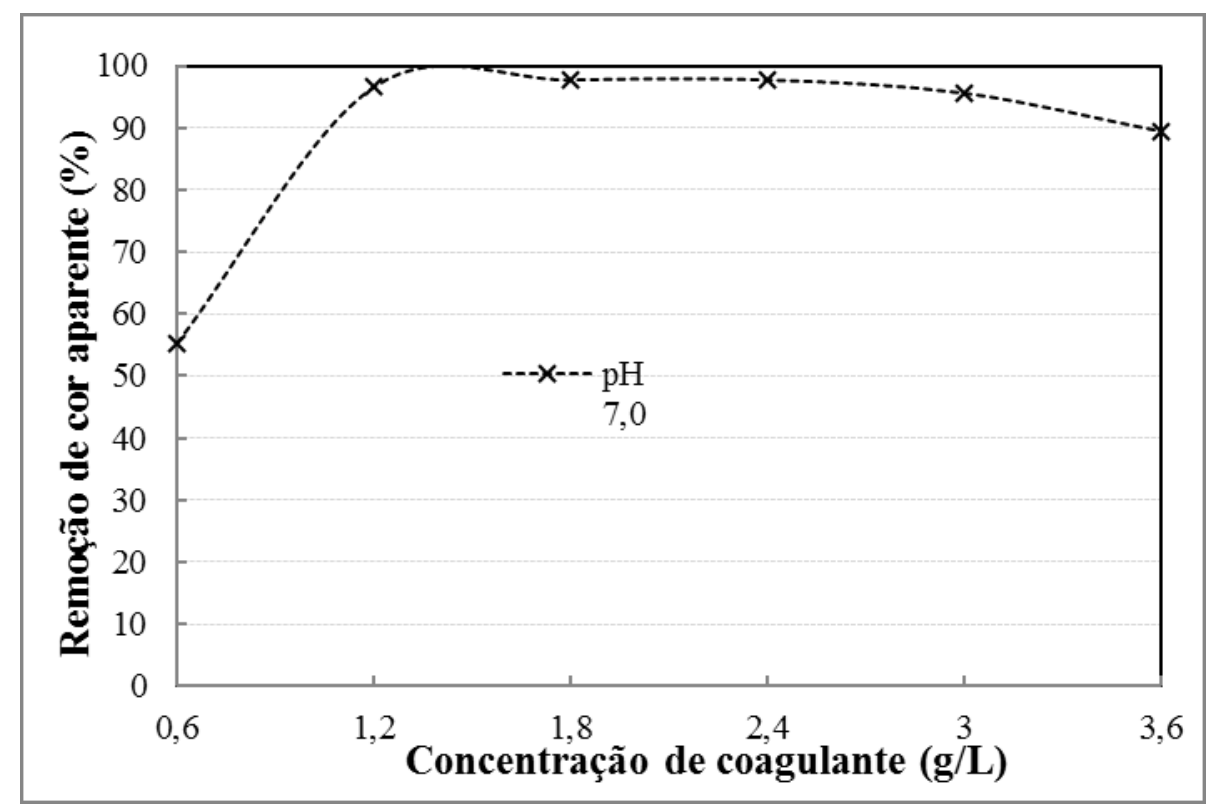


Pode-se observar que as remoções máximas de cor ocorreram nas concentrações de 1,2 a 2,4 g/L de coagulante. Nestas condições, as remoções de cor foram de quase $100 \%$. Em concentrações acima de 2,4 g/L, as taxas de remoções começaram a decair.

As eficiências de remoção de cor empregando concentrações de 0,6 a 3,6 g/L de tanino em pH 7,0 variaram de 55,26 a $97,81 \%$.

A Figura 3 apresenta a eficiência de remoção de turbidez com o coagulante tanino.

Figura 3: Remoção de turbidez utilizando tanino

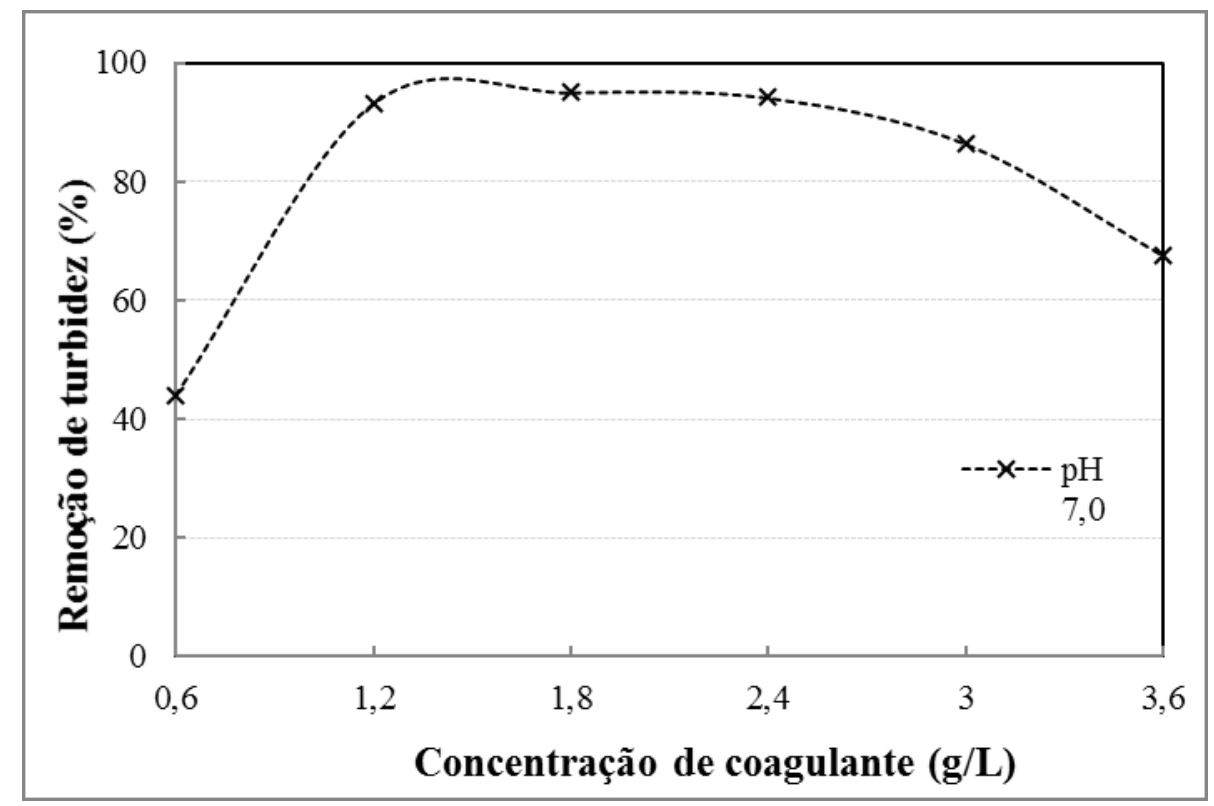

A análise de turbidez permitiu verificar que as melhores concentrações de coagulante para a remoção deste parâmetro também foram também de 1,2 a 2,4 g/L. Nestas concentrações, as remoções foram superiores a $90 \%$.

Na concentração de coagulante de 0,6 g/L, pôde-se notar um comportamento similar à remoção de cor, somente atingindo taxas de remoção mais altas com o aumento da concentração de coagulante. Para concentrações de coagulante acima de $2,4 \mathrm{~g} / \mathrm{L}$, a eficiência de remoção de turbidez começou a sofrer decréscimo.

A eficiência de remoção de turbidez nas concentrações de 0,6 a 3,6 g/L de tanino, em pH 7,0, foram de 44,04 a 95,06\%. 
A Figura 4 apresenta a eficiência de remoção de DQO com o coagulante tanino.

Figura 4: Remoção de DQO utilizando tanino

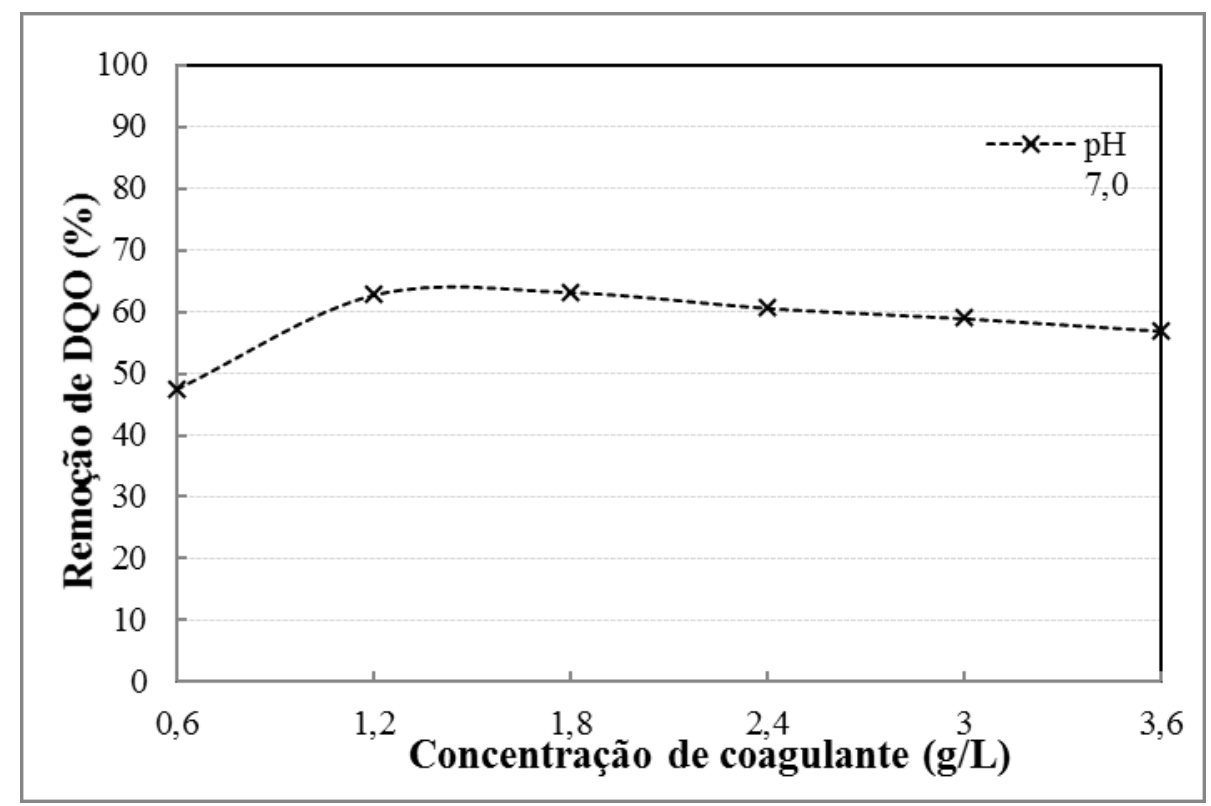

Para o tratamento utilizando o coagulante natural, a remoção máxima de DQO obtida foi de aproximadamente $70 \%$. Os melhores resultados foram nas concentrações de 1,2 e 1,8 g/L.

No caso da DQO, houve um menor decréscimo na taxa de remoção com o aumento da concentração de coagulante, em relação à cor e turbidez.

As eficiências de remoção de DQO empregando-se concentrações de 0,6 a 3,6 $\mathrm{g} / \mathrm{L}$ de tanino, em $\mathrm{pH} 7,0$ foram de 47,55 a $63,18 \%$. Assim, verificou-se taxas de remoções mais baixas para este parâmetro.

\section{3 - CONCLUSÃO}

A caracterização do efluente demonstrou que o mesmo apresenta altos valores de cor aparente e turbidez, enquanto que a quantidade de matéria orgânica encontrada foi menor que em outras pesquisas. 
$\mathrm{O}$ tratamento do efluente de curtume em pH 7,0 utilizando o tanino comercial resultou em uma elevada taxa de remoção de cor aparente e turbidez, enquanto que a remoção de matéria orgânica, apesar de também ter sido alta, não foi equivalente a dos outros parâmetros.

Desta forma, um possivel tratamento complementar à coagulação/floculação/decantação poderia aumentar a eficiência de remoção de matéria orgânica do efluente.

\section{REFERÊNCIAS}

APHA - American Public Health Association. Standard methods for the examination of water and wastewater. Washington D.C., 20th ed, 1998.

CARVALHO, M. J. H. Uso de coagulantes naturais no processo de obtenção de água potável. Dissertação (Mestrado em Engenharia Urbana) - Centro de Tecnologia, Universidade Estadual de Maringá, Maringá, 2008.

FREITAS, T. C. M., MELNIKOV, P. O uso e os impactos da reciclagem de cromo em indústrias de curtume em Mato Grosso do Sul, Brasil. Engenharia Sanitária e Ambiental, v. 11, n. 4, p. 305-310, 2006.

KURT, U., APAYDIN, O., GONULLU, M. T. Reduction of COD in wastewater from an organized tannery industrial region by Electro-Fenton process. Journal of Harzadous Materials, v. 143, n.1-2, p. 33-40, 2007.

PASCOAL, S. A., LIMA, C. A. P., SOUSA, J. T., et al. Aplicação de Radiação UV solar e artificial sem tratamento fotocatalítico de efluentes de curtume. Química Nova, São Paulo, v. 30, n. 5, p. 1082-1087, 2007.

ÖZACAR, M.; SENGIL, I. A. Evaluation of tannin biopolymer as a coagulant aid for coagulation of colloidal particles. Colloids and Surfaces A: Physicochemical and Engineering Aspects, v. 229, n. 1-3, p. 85-96, 2003.

VAZ, G. L. G., KLEN, M. R. F., VEIT, M. T., et al. Avaliação da eficiência de diferentes agentes coagulantes na remoção de cor e turbidez em efluente de galvanoplastia. Eclética Química, v. 35, n. 4, p. 45-54, 2010. 